\title{
O Véu, a Bruma, a Tela e a Face - $O$ negativo do documental na fotografia de imprensa ${ }^{1}$
}

1. Trabalho apresentado ao GT "Produção de Sentido nas Midias", do XV Encontro da Compós, Unesp, Bauru, SP, em junho de 2006.

Kati Eliana Caetano SANDRA FISCHER Universidade Tuiuti do Paraná / UTP 


\section{Resumo}

Embora destinada, a princípio, a homologar visualmente as informações e valores expressos no texto verbal, a fotografia de imprensa pode ganhar ares de suficiência capazes de suscitar leituras mais amplas do que aquelas a que se reporta. A escolha de uma imagem, tanto pela temática manifesta quanto pelo agenciamento de dispositivos discursivos e plásticos, condiciona percursos interpretativos que parecem validar certezas ou suscitam novas reflexões, instituindo regimes de interação distintos com o leitor. Para tanto, a imagem se reveste de marcas que a aproximam ou distanciam de sua pressuposta "essência" fotográfica.

\section{Palavras-chave}

fotografia de imprensa, comunicação visual, imagem.

\section{Abstract}

Although firstly destined at promoting visual homologation to information and values expressed by the verbal text, the press photograph can acquire a sort of autonomy that is capable of amplifying the reading possibilities. An image selection, both for the manifest thematic and for the arrangement of discursive and plastic devices, conditions interpretative paths that seem to validate certainties or that incite reflection, establishing with the reader distinct interaction regimes. For that, the image is embodied with marks that approximate or distance it from its presupposed photographical "essence".

\section{Key words}

press photograph, visual communication, image. 


\section{Introdução}

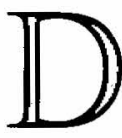

ois fatos contemporâneos merecem ser citados para abertura deste trabalho, pelas reflexões que suscitam a propósito do papel do fotojornalismo na construção de regimes de sentido e de interação que estabelecem com os leitores.

O primeiro diz respeito ao comentário feito pelo crítico de arte norte-americano Max Kozloff (In: Castro, 1998, p.70), por ocasião da mostra Hecho em Latinoamérica II, realizada no México, quando, diante da diversidade e natureza do material selecionado para a mostra, e na qualidade de jurado, fez a seguinte declaração: "los límites entre el espacio histórico del fotoperiodismo y esta visión fantástica sin tiempo, son mucho más fluidos que en mi propia cultura". Essa observação fundamenta, por sua vez, o pensamento de Fernando Castro, no artigo relativo à análise das fotografias selecionadas, para quem: /.../ "las classificaciones de género no siempre están claramente ilustradas en la fotografia latinoamericana. Documentar, por ejemplo, no excluye la ambigüedad o la fantasía." $(1998$, p. 70$)$

O segundo fato nos remete à premiação do concurso World Press Photo de 2005, que atribuiu o primeiro lugar à fotografia do indiano Arko Datta, da agência de notícias britânica Reuters. A imagem ganhadora, em cores, mostra a dor de uma mulher da região de Cuddalores que chora a morte de um familiar, vítima do tsunami ocorrido na região asiática, considerado o maior desastre natural do início do século XXI. A revista de fotógrafos Cuartoscuro explica que o presidente do jurado, Diego Goldberg, qualificou a imagem de "verdadera foto de actualidad, em la que queda plasmada de forma clara la visión del fotógrafo", esclarecendo ainda que o jurado teve 
que deliberar entre 69190 fotos, enviadas por 4266 fotógrafos procedentes de 123 países. (www.cuartoscuro.com.mx/71/artículos.html)

Compreender o sentido de uma foto em que "está plasmada a visão do fotógrafo" ou reconhecer a fluidez dos limites entre certo tipo de foto artística e documental, implica necessariamente duas posturas: colocar-se do lado do fotógrafo, assumindo o máximo possível o seu olhar, e o que ele filtra da sua percepção-emoção, e admitir que os processos cognitivos, de ordem intelectiva, nem sempre excluem favorecimentos emotivos, fundados na relação sensível entre os participantes de um ato comunicativo. Para estar do lado do fotógrafo, porém, não basta querer; é preciso que dispositivos visuais sejam acionados em diferentes instâncias do discurso de modo a levar o leitor/espectador a se deter diante de uma imagem, sobretudo quando ela "ilustra" um texto verbal e concorre com outras na superfície de uma página, e, no ato contemplativo, que ela não só expresse o verbal, mas que o diga de outra maneira, à sua maneira enquanto sistema simbólico visual, e a ele acrescente outras imagens, valores, suscite dúvidas, novas leituras, vontade de entender, saber mais. É conhecido o ritmo em que as informações se processam na produção de um diário, o recurso a imagens de bancos de dados, o papel do editor-redator na seleção e organização das matérias, etc. Não pretendemos aqui falar de uma intencionalidade subjacente ao ato fotográfico que se reconstrói sem mácula até o produto final da sua divulgação numa folha de jornal, mas do compartilhamento de percepções e sensações que certos discursos provocam pelo agenciamento formal que fazem de suas unidades constitutivas.

Este é o objetivo do presente ensaio: proceder à leitura de algumas imagens fotográficas de jornalismo que têm a novidade do visual, portanto que não preenchem apenas uma função ilustrativa, e que favorecem a diluição do gênero documental em proveito de uma fala múltipla, que remete tanto ao fato pontualmente ilustrado quanto ao mergulho em outros dados, no mesmo sentido em que Roman Jakobson (1970, p. 130 ), ao falar da singularidade da função poética, a definia como uma manifestação da linguagem caracterizada pela projeção, no eixo das combinações, do princípio de equivalência do paradigma, aqui entendido não só como paradigma verbal, mas iconográfico, cultural no sentido amplo. 
A idéia é que ao falar da fotografia, sobretudo do fotojornalismo, situamo-nos num quadro de expectativas de referencialidade mais próximo de seu caráter indicial e nos surpreendemos ao descobri-la, em certos momentos, como imagem, portanto como simulacro. Sua natureza parece definir-se assim numa linha contínua entre a indicialidade e o simbólico, entre o altamente figurativo, iconizado, comprometido a conferir efeitos de realidade ao referente, como se ele existisse a priori e a foto não fizesse mais nada do que captá-lo, e o figurativo em ato de construção, com ganhos de sentidos gerados não só pelo que a foto comporta de indicial, mas sobretudo pelo que implica de seleção, organização, colocação em relevo, criando conotações passíveis de serem compreendidas graças ao universo pragmático de referências comum evocado. Vincular a foto a esse valor de imagem não significa sempre associá-la aos sistemas pictóricos, mas situá-la, na sua condição mesma de fotografia, no domínio das linguagens utilizadas pelo homem no estabelecimento de interações e comunicações com os outros homens.

Ao discutir a fotografia da perspectiva de sua relação com a realidade, Floch (1986, p. 20) já havia desenvolvido um modelo operacional, fundado sobre quatro categorias gerais (referencial, mítica, oblíqua e substancial), que formalizava diferentes concepções de linguagem fotográfica subjacentes. $O$ presente trabalho, no entanto, vai numa outra direção: falamos da relação da imagem com o enunciatário na sua forma de complementação, preenchimento ou explicação do texto verbal, ou da imagem na afixagem (Fontanille, 2005 , p. 37-76) jornalística enquanto estratégia de conjunção com o verbal para a eficácia comunicativa.

No âmbito desse tipo de preocupação é que interessa perguntar : do que elas, as imagens, nos falam, por que paramos nosso olhar sobre as mesmas? Com o intuito de responder essa questão, passamos por 4 fotos que têm em comum o fato de implicarem leituras ambivalentes, sobretudo quando reagrupadas nesse conjunto. $\mathrm{O}$ que permite reuni-las num corpo homogêneo é que podem ser abordadas por dois regimes de interação com o destinatário, metaforizados em suas próprias organizações enquanto linguagens: implicam, duas a duas, os atos de velar ou desvelar os referentes a 
que se reportam, aproximando ou distanciando-os de nossa apreensão, e com isso reforçando estereótipos ou despertando reflexões críticas.

Em princípio, cabe discutir o que essas 4 fotos têm em comum, ou seja, o que nos permite considerá-las representações fotográficas de vidência-evidência (Fontcuberta, 1996, p. 8-15) no sentido de descoberta ou percebimento?

Sobre esta questão, é relevante lembrar que as primeiras formas de reprodução de um objeto ou cena projetados sobre uma superfície se processavam por meio de telas, tecidos ou vidros (depois pela mediação da lente), que permitiam uma certa transparência, ainda que filtrada, do referente. Ora, pode-se dizer que as imagens selecionadas elevam ao valor de metáfora essa condição inerente ao ato fotográfico. A primeira foto (Fig. I) extraída da $1^{\text {a }}$ página do diário Folha de São Paulo de 18/06/2005, sobre as eleições no Irã, apresenta mulheres muçulmanas, cobertas com véus negros, dispostas em fila para votação à presidência do país, fotografadas de costas. Entre elas, a figura de uma menina, também de véu na cor branca, volta-se para olhar o fotógrafo no momento do clique (Patrick Baz - France Presse). A segunda foto (Fig. II), retirada também da $1^{\text {a }}$ página da FSP, do dia 23/04/2005, ilustra o tema do conflito Israel-Palestina e representa um grupo de judeus ortodoxos em oração para a Páscoa Judaica, durante período de trégua, visualizados através de uma cortina de fumaça provocada pelo fogo (Oded Bality - Associated Press). A imagem seguinte (Fig. III), extraída da primeira página de Caderno Especial da FSP, intitulado A morte do Papa, de 03/04/2005, retrata um menino fotografado em confessionário no Vaticano, aparentemente em foto encenada (Marco Longari - France Presse). Por último, uma foto brasileira retirada da revista Photógraphos, de artigo especial dedicado ao fotojornalismo (Oliveira, 2005, p. 14-27), expõe mais uma cena cotidiana de assassinato aparentemente ocorrido na periferia de alguma grande cidade brasileira, tendo em primeiro plano a figura desproporcional do rosto de um menino que sorri para as câmeras (Evandro Teixeira, p. 22). Nas 3 primeiras, a presença de um filtro interpondo-se entre a imagem representada e a percepção do leitor é evidente e se manifesta em diferentes instâncias nos níveis discursivos e no plano da expressão plástica. 


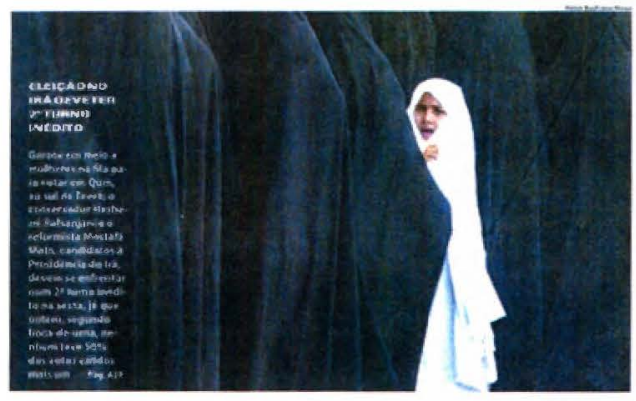

Figura I - $O$ véu

Fonte - FSP, 18/06/05
Figura II - A bruma Fonte- FSP, 23/04/05.

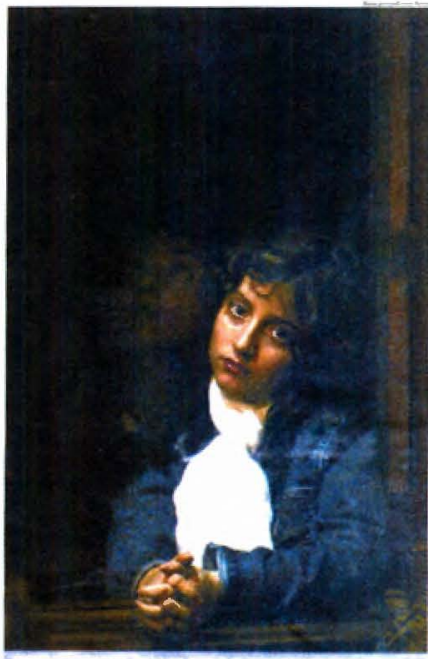

Figura III - A tela

Fonte - FSP, 03/04/05.
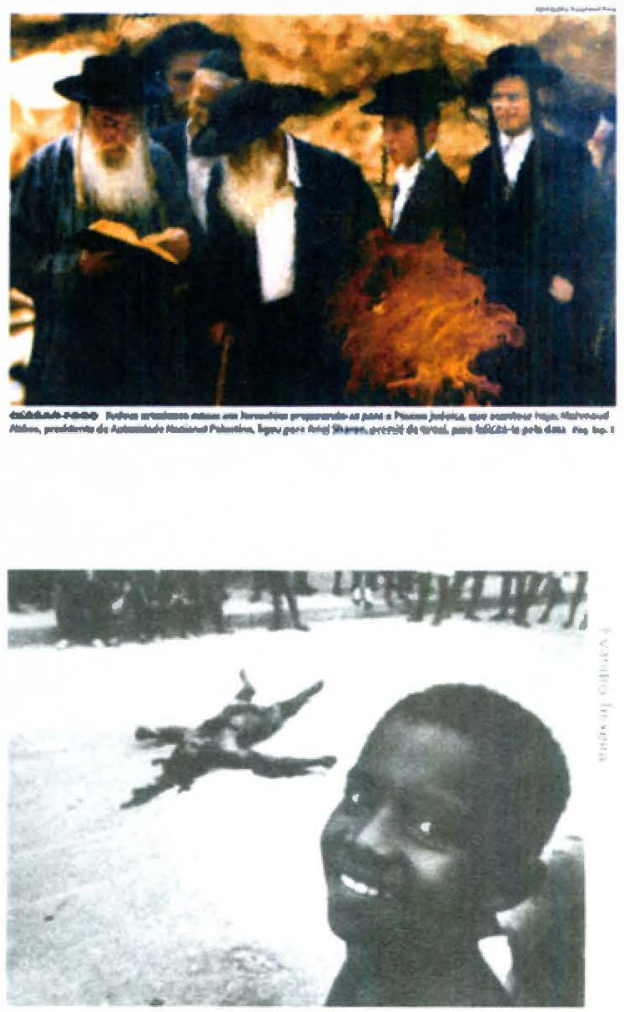

Figura IV - A face

Fonte - OLIVEIRA, 2005, p. 22. 
$\mathrm{Na}$ foto das iranianas, os véus preto e branco dão a configuração fundo-forma à cena, instituindo dimensão aos corpos, numa primeira tomada emergidos como uma massa uniforme, e profundidade espacial ao todo. $\mathrm{Na}$ imagem dos judeus em oração, é a fumaça que compõe o cenário brumoso sob o qual as figuras têm seus contornos diluídos em efeitos de uma técnica impressionista. $\mathrm{Na}$ figura do menino de olhar melancólico, sem véu e sem bruma, trata-se da própria lógica pictórica da imagem, portanto de um agenciamento dos formantes plásticos da expressão, que determinam o filtro de leitura propiciando à fotografia a sensação de uma tela. $\mathrm{O}$ próprio texto verbal fortalece esse viés interpretativo ao afirmar "Como um quadro!"; e ficamos perplexos diante dessa "pintura", duvidando de que não se trata de um quadro.

Véu, bruma e tela correspondem, assim, a modalidades de manifestação sensível presentes, respectivamente, nas instâncias discursiva e plástica (nitidez vs embaçamento, contrastes cromáticos e de luz e sombra). A idéia de cobertura ou filtro que encerram acentua a relação descontínua entre o que representam e suas manifestações simbólicas, refuncionalizando a fotografia em sua condição de testemunha ocular para posicioná-la como uma linguagem que constrói subjetivamente a realidade. Do agenciamento minimal da foto I (eleições iranianas), passando pela iconicidade esparsa da técnica impressionista da foto II (israelenses orando), até o naturalismo renascentista da foto III, o que observamos é a força centrípeta da imagem se impondo como estratégia de ajustamento ao contexto do jornal e deste ao contexto de outras mídias na fase da propalada crise da imprensa escrita.

Resta a referência à foto IV, com a tomada da face, e, por pressuposição, a possibilidade de analisá-la também pelo que ela pode comportar de máscara. Para essa relação, convém retomar o sentido dicionário deste termo - máscara - enfatizando alguns de seus conceitos: peça destinada a cobrir o rosto, para disfarçar a pessoa que o põe; molde que se tira do rosto dos cadáveres; e, por fim, fisionomia, rosto, face. Numa mirada inicial, a foto descreve o corpo de um morto estendido ao fundo, em tomada ligeiramente apagada no segundo plano, e observado por outras pessoas cujas presenças 
estão insinuadas por pernas e pés. $\mathrm{Na}$ frente, o rosto de um garoto posicionado na linha vertical em relação ao corpo do fundo, como se tivesse se interposto abruptamente entre a objetiva e o cadáver no momento da captura, obstruindo a visão do que seria o fato principal a ser retratado, e dando cara aos rostos invisíveis.

A mesma descontinuidade operada nas fotos anteriores reaparece aqui, agora no âmbito do próprio enunciado, entre primeiro e segundo plano. Essa dupla espacialidade constrói-se sobre pares francamente opositivos: corpo estendido na horizontal vs corpo vertical; inerte vs dinârnico; passivo vs ativo; objeto fotográfico vs sujeito que se faz fotografar; face oculta vs face exposta; tragédia vs alegria; morte vs vida. Pode-se identificar a lógica da máscara nesse esquema, uma vez que ela pode velar o sorriso pela carranca ou a tristeza pelo riso "sardônico". Assim também, ela encarna possíveis papéis actanciais: em contraste com o trágico da morte, a felicidade da vida que irrompe no sorriso escancarado, inscrevendo uma duratividade na dupla ruptura temporal imposta tanto pela morte quanto pelo ato fotográfico. A entrada do garoto na imagem aparece como uma força que trarısgride essa inevitabilidade do corte, da parada, inserindo movimento, energia, novidade ao cotidiano saturado das mesmas imagens.

Por esse viés, tal foto pode ser associada àquela das iranianas, criando um subgrupo no conjunto das 4 , marcado figurativamente pela presença da criança, com toda a carga semântica de inocência e transgressão involuntária que pode conter, e enunciativamente pela convocação do espectador para o quadro pela visão recíproca que seus olhares nos impõem. Não por acaso, as outras duas imagens, dos judeus e do menino italiano, foram agrupadas num outro pólo, aquele do distanciamento. Pode-se questionar se a foto do menino no Vaticano não se enquadraria no primeiro grupo, tendo em vista que parece estarmos diante de um mecanismo enunciativo similar. Ora, o menino italiano está configurado segundo uma lógica do retrato $\mathrm{cm}$ seu estilo mais suntuoso, colocando-o num espaço-tempo outro do que aquele do momento enunciativo (o olhar da pintura), e, talvez por decorrência, ele não nos olha; seu olhar parece se perder no devaneio, numa espécie de indiferença altiva ao que o cerca cujo efeito passional está mais próximo da melancolia. 
Em suma, as imagens foram selecionadas em função desse estatuto: porque implicam mais do que a sua inserção ilustrativa ou complementar ao texto verbal exigiria; não se trata, portanto, de detectar apenas aí o caráter polissêmico da imagem, mas de pôr em relevo o fato de que em tais contextos a imagem acentua traços de sentido mais amplos do que aqueles que a legenda verbal indica, do que deriva, necessariamente, a demanda de um mergulho do leitor no entrelaçado sistema de seus subcódigos culturais. Pode-se dizer que o mesmo é levado a parar sobre a imagem e a se perguntar por que ela e não outra complementa o conteúdo veiculado pelo verbal. A fotografia dos judeus em oração, durante o cessar fogo, mal divisados pela bruma que os envolve, diz algo a mais do que essa trégua numa luta atávica; o menino em estado contemplativo no confessionário convoca referências e leituras que extrapolam a imediaticidade do drama da morte de João Paulo II; a menina muçulmana que nos convoca com seu olhar, única luz no meio do fundo negro, e o menino brasileiro com seu largo sorriso se impondo à presença da tragédia urbana cotidiana, são mais insistentes como traços de conteúdo do que a factualidade a que se reportam.

Antes de dar desenvolvimento à discussão dos dois grupos assim representados, é necessário, no entanto, abordá-los em seus contextos - o espaço das primeiras páginas.

\section{O papel narrativo das primeiras páginas}

São suficientemente conhecidos os valores assumidos pelas informações da primeira página. Nas distintas formas de afixagem, Fontanille (2005, p. 37-76) reitera tal papel ao afirmar que, nesse espaço, tudo adquire a importância da intensificação de uma matéria, pois aí as imagens, legendas, manchetes, títulos e subtítulos colocam em destaque notícias ou informações que devem ser priorizadas. Constituem, em suma, estratégias hierarquizadas no conjunto de outros procedimentos de disposição, combinação ou composição. No caso dos jornais, por exemplo, podemos dizer que é preciso atrair a atenção, entre tantas chamadas, para a pluralidade visual interna, em princípio cansativa já na avaliação de sua extensão, principalmente 
quando se considera a €conomia da televisão, da internet ou mesmo do rádio. Por isso, não só atrativas, tais informações verbo-visuais devem despertar o gosto da explicação, do detalhamento, da justificação, uma vez que o conteúdo nuclear está ali suficientemente tematizado e, no caso das imagens, figurativizado. Como bem nos lembra o autor:

$A$ ostentação, a seleção $e$ a intensificação supostamente desencadeiam um processo de captação e uma expectativa de leitura, mas também, e muito freqüentemente, uma frustração latente que demanda uma reparação posterior. Em todos os casos, um interesse e um querer saber, mais ou menos intensos e concentrados, são despertados. (Significação e visualidade, 2005, p. 47)

Se a chamada da primeira página desincumbe-se bem de seu papel de despertar interesses por mais informações sobre um tema, podemos dizer que ela manifesta uma dupla determinação: a de parecer refletir inocentemente ou naturalmente os acontecimentos da véspera e a de se posicionar como a geradora das informações relevantes, o que condiciona de certa maneira o percurso da leitura. A par dessas duas funções, porém, é necessário considerá-la no quadro de um programa narrativo que trabalha a tensão da espera e da satisfação, para a solução da qual a leitura das páginas internas apareça como necessária e não contingente. No entanto, enquanto a primeira página de um jornal (ou pelo menos as primeiras de cada caderno) busca se destacar pela excepcionalidade do dizer, mais do que pelo dito, uma vez que nem sempre fatos extraordinários acontecem, é importante esclarecer que as fotos internas, em geral, reiteram o "já visto", como se os programas de espera de novidade impusessem um limite para suportá-las: é preciso voltar ao lugar comum, dotar o jornalisrno de sua suposta missão de esclarecedora dos fatos e possibilitar ao leitor o domínio dos acontecimentos do mundo da maneira mais prevista possível. 


\section{Organizando as imagens}

Voltemos ao nosso raciocínio inicial - os dois grupos de fotos - retomando, a princípio, a distinção de Joan Fontcuberta (1996, p. 815) entre vidência e evidência. Fundamentado na existência de um duplo movimento da fotografia assentado seja no seu papel documental, em que os fatos se evidenciam visualmente, seja no seu valor heurístico, de descoberta, portanto de vidência, o autor propõe que a vidência, normalmente vinculada ao reconhecimento do que foi, seja também reconhecida pela função de vislumbrar o futuro. Emprestamos esse duplo conceito de vidência com um leve deslocamento de conteúdo, aqui interpretado como afirmação de um efeito de sentido de temporalidade - passado e futuro - que pode estar inscrito na imagem por meio de dispositivos discursivos e plásticos.

Partindo desse pressuposto, podemos lançar a questão: até que ponto tais fotos condensam informações capazes não só de expor visualmente os fatos relatados pelo verbal, mas principalmente de caracterizá-los numa situação contextual mais ampla em que nossos valores se sintam confirmados em suas representações ou, ao contrário, se vejam confrontados a novidades? Assim como as imagens puderam se organizar em função do caráter pictórico ou fotográfico de suas estruturas, respectivamente as fotos dos judeus em oração e do menino católico no Vaticano como um grupo (I) e as imagens das iranianas e do menino brasileiro em outro bloco (II), duas novas distinções se evidenciam.

O grupo I sugere evocações ligadas ao passado: na imagem dos judeus, pela indumentária, pelo ritual, pela gestualidade, pela tradição e pela perspectiva enunciativa, formalizado tanto plasticamente pela presença da bruma, quanto pelo estilo impressionista obtido graças à imagem tremida e esfumaçada; na figura do menino no Vaticano, pelas vestes, pela tradição, pelo distanciamento do olhar e pelo estilo renascentista da composição visual, em colorido escuro e denso, destacando com potência a figura do menino sobre o fundo negro do qual se insinua a imagem de uma mulher suplicante olhando para o alto. A impenetrabilidade das duas imagens resulta da sensação de que requerem uma leitura iniciática 
para sua compreensão, do que deriva o distanciamento entre o eu e o outro, confirmado na sua estranheza ou estrangeiridade. Cria-se então o cenário imagético ideal para reiterar os valores de que há situações, sejam elas sociais ou naturais, como a morte, e pessoas ou povos, com suas culturas, cuja compreensão nos escapa; enfim, fotos que parecem homologar certezas e confirmar evidências. Configurase, com a seleção dessas imagens, o delineamento de uma outra espacialidade, que não a do eu, como diria Barthes, criando uma espécie de realidade da qual estamos protegidos (Barthes, 1990, p. 36). É possível dizer que estratégias desse tipo, na seleção-composição de imagens, têm a facilidade de instituir regimes de interação capazes de inscrever o leitor na condição de mero observador dos fatos, do que pode derivar, por exemplo, seu distanciamento em relação às chamadas imagens-choque.

O grupo II marca-se pelo que é, fotografia, enfatizada especialmente pelo efeito de preto e branco. Poder-se-ia argumentar, do mesmo modo, que a foto das iranianas remete ao passado, a uma tradição. Se isso é verdadeiro no que toca ao conteúdo das vestes e à posição das mulheres adultas, não podemos dizer o mesmo a respeito da menina. Contrariando a tradição, ela se volta para olhar o fotógrafo, e por meio dele o enunciatário. Curioso ou contraventor, seu olhar se protege na espontaneidade infantil, ao mesmo tempo que anuncia a possibilidade de um novo tempo, traduzindo visualmente o espírito das eleições de que as mulheres participam. Não queremos com isso afirmar a existência efetiva de mudanças, mas a impressão que tais fotos causam, reiterando o discurso verbal. A imagem em foco não se limita apenas a esse sentido: ao romper plasticamente a densidade escura da imagem em que se convertem as figuras anônimas, de rostos ocultos, das mulheres de negro, a figura da menina homologa no plano da expressão a ruptura operada no plano do conteúdo, qual seja dar visibilidade a um rosto, extraí-lo da massa uniforme do outro, dotando o "estranho" de uma feição humana a despeito das diferenças, do jogo de valores em causa, e com isso reconhecendo, por baixo das vestimentas culturais, a condição humana do ser criança.

Nessa foto sobre as eleições no Irã é possível seguir o percurso, no plano da expressão, dos níveis de pertinência semiótica 
de que fala Fontanille, aqui aplicados à análise da fotografia de imprensa (2005, págs. 86-87): interação entre matéria e jogo de forças figurativizado pelo preto e branco; redução desse grau de figuratividade levando ao reconhecimento de uma fresta de luz numa grande mancha negra; campo sensível da luz sobre as roupas com implicações não só visuais mas sobretudo táteis, maior aproximação da imagem sobre o espectador. Como conseqüência dessa disposição tem-se uma estrutura mais inclinada à abstração, à idéia de perda da individualidade, só rompida pela nesga de luz que se vira para o leitor e que resulta, de acordo com a visada teleológica, uma comunicação sustentada fortemente sobre a emoção. Ela pouco informa sobre as eleições, mas conota uma nova possibilidade de transformação, mudança que nos interroga mais do que promete. Pode-se afirmar que a cena evoca a cultura, profundamente impregnada de religiosidade: os traços figurativos estão a meio caminho de uma formação geométrica, em que as mulheres compõem um fundo chapado negro e a garota uma solução de continuidade branca rasgando a obscuridade, à feição dos pictogramas, que, na acepção de J. Fontanille (2005),

compõem-se como um texto: o olho percebe e recompõe a distribuição das figuras no espaço plano, e mesmo em vários niveis de profundidade, mas hesita em colocá-los nesse espaço tridimensional que seria necessário a uma leitura icônica; os planos de fundo são apenas telas sucessivas e sem espessura; o leitor hesita, assim, entre a simples superficie de inscrição e o espaço perspectivo. (p. 122)

Essa estrutura gera implicações na apreensão da foto, que não se submete ao exercício de um mero reconhecimento descritivo (mulheres iranianas na fila de votação), mas passa a ser evocada num quadro de leituras em que está implicado pragmaticamente $o$ conhecimento que o espectador tem dos países islâmicos, e do Irã em particular, das representações que formula da imagem da mulher nessas nações; do imaginário ocidental concebido a respeito das 
mulheres que se cobrem, em suma, das iranianas que vão às urnas para decidir os destinos de seu país. Em outros termos, o papel supostamente documental da foto se neutraliza em favor de uma ambivalência dos seus sentidos, uma vez que, justamente no âmbito da objetividade dos fatos a ser conferida à imagem (na sua condição de complementar do texto verbal) é que parece, à primeira vista, ser improcedente a escolha de uma foto contrária às expectativas do senso comum, colocando em primeiro plano a criança iraniana, que não se cobre totalmente, não se esconde, não vota e nos olha, ao olhar para o fotógrafo.

A foto do menino de riso escancarado não tem o minimalismo da anterior, parecendo, do ponto de vista de sua composição, mais fotográfica. Ela opera com um primeiro plano destacado em oposição ao ambiente de fundo, espaço de concretização da violência, relegado a uma dimensão mais profunda da superfície da imagem na seqüência de um espaço vazio que delimita com folga as zonas de presença do menino e do morto estendido no chão, assim como deste e dos observadores. A emergência da face da criança em primeiro plano, desproporcional em relação ao restante da imagem, tem a função de um bloqueio icônico, de efeitos surreais, ao olhar do leitor, ou de um filtro entre este e o tema da violência. Seu impacto é o da descoberta de uma oposição que pode adquirir múltiplas faces: do morto vs vivo, do sujeito passivo vs sujeito ativo, da tristeza e da alegria, e, por extensão, como metáfora do próprio ato fotográfico, do documentado e do documental, em outros termos, daquilo que é eleito ou se elege como foco da reportagem fotográfica, portanto do caráter arbitrário do fotojornalismo.

Nesse sentido, pouco interessa o fato de que a foto seja analógica ou digital, original ou manipulada, porque ela deve ser contada como uma escolha dentre outras, como uma combinação passivel de ser realizada entre tantas potencialidades oferecidas pelas tecnologias atuais e como um produto final a ser veiculado em nome, e no lugar, de uma realidade que se pretende registrar visualmente. Assim, a foto da menina iraniana anuncia uma situação contingente, possível de ser transformada, ainda que restando na tradição, enquanto a imagem do menino brasileiro concretiza uma ação efetiva, ainda 
que desconcertante, e capaz de orientar em direção contrária os humores do leitor diante do documentado. É com esse valor, e deslocamento de conceito, que empregamos acima a distinção entre vidência para o passado ou para o futuro de Fontcuberta: a primeira imagem insere o fato num contexto mais amplo do que o das eleições, situando o leitor no fato presente com base num universo de referências inscrito em imagens do passado e aproximando-o do que lhe parece distante; a segunda retira-o do engessamento visual de uma cotidianidade, povoando sua imaginação de indagações potenciais: entre tantas outras, o que esse sorriso anuncia e em que medida nos cativa ou desorienta?

$\mathrm{Na}$ verdade, o rosto sorridente da criança em face da morte, separados por um espaço significativo que os distancia plasticamente, pode ser comparado ao sorriso de Carlitos diante da tristeza. Intrigado sobre o modo como Carlitos encarava a vida, Einsenstein (1969, p. 207-208) encontrou a resposta numa passagem de $A$ condição humana (André Malraux), em que garotinhos chineses riem da cena de uma minúscula mulher chinesa, sua mãe, que esbofeteia o marido morto, deitado na cama como se estivesse bêbado:

E a mulher o esbofeteia porque, morrendo, ele a condena a morrer de fome juntamente com as crianças de alegres olhos de cristal...

/.../ Quando penso em Chaplin eu o vejo sempre sob o aspecto de um desses chineses risonhos que acham tão engraçado ver virar para um lado e outro a cabeça desse homem corpulento sob as taponas daquela mulher minúscula.

Que importa que essa chinesa seja a mãe deles e o homem o pai deles, um desempregado? Que importa, principalmente, que ele esteja morto?

Eis o segredo de Chaplin. Eis o segredo de seu olho. /.../ ...Ver as coisas mais terriveis, as mais dolorosas, as mais trágicas, com os olhos de um garoto risonho. 


\section{Considerações finais}

A leitura das 4 fotos selecionadas desenvolveu-se sobre alguns eixos significativos para o depreendimento de conclusões. De um modo geral, podemos afirmar que a fotografia, mesmo em sua função presumidarnente documental na imprensa, assume configurações que a fazem transitar entre o pictórico e o fotográfico propriamente dito, segundo a perspectiva corrente relacionada a essas duas ordens de mediação simbólica entre o homem e o mundo. A oposição entre pictórico e fotográfico se estabelece na dimensão de uma linha contínua, que tem como corolário formas de expressão relacionadas à diluição do figurativo ou a sua iconização, incluindo técnicas como a da alta nitidez ou embaçamento, a passagem direta entre as zonas cromáticas, criando efeitos de contraste, ou, ao contrário, o recurso aos esfumaçamentos que diluem e serenizam as mudanças perceptivas, além de outros dispositivos constitutivos do plano da expressão das imagens. Nos exemplos estudados, o pictórico se encaminhou para a ação de confirmar evidências, cujo resultado paradoxal foi o de propiciar a impressão de nos velar a compreensão da realidade. A composição fotográfica assumida criou, ao contrário, perspectivas novas; incitou reflexões que dispõem em segundo plano o tema-foco da reportagem. Nesse sentido, instaurou vidências com projeções temporais que induziram ao vai-e-vem permanente entre passado e futuro tendo como âncora o fato representado no presente enunciativo.

A escolha das imagens foi considerada pertinente exatamente pelo efeito inusitado que incitam: no senso comum, de acordo com o conhecimento que temos do que é a fotografia, as expectativas seriam a de que o pictórico levaria à vidência, ao conotativo, enquanto o fotográfico inscreveria o referencial e o figurativo dado a priori. Em outros discursos, obviamente as combinações serão distintas; o que é constante é a caracterização da imagem, também da fotográfica, como simulacro em construção (Landowski, 1992, p. 165-172), condicionada a modos de existência definíveis em função de contextos de ajustamento, formas de afixagem e visibilidade, assim como de mecanismos enunciativos de interação. 
A imagem transita, assim, entre o velar-desvelar, o pictórico e o fotográfico, o referencial e o simbólico, a vidência e a evidência, o figurativo icônico e a "desiconização" (pictorialização), o figurativo como representação de algo dado a priori e o figurativo construído, em suma, em efeitos de sentido de objetividade-subjetividade, com impressões de aproximação e distanciamento decorrentes de todas essas escolhas e de suas múltiplas combinações. O que é certo é que cada uma delas desencadeia sentidos e interações diferentes, tanto faz se se trata do jornalismo impresso ou digital, o que descaracteriza a idéia de que com o jornalismo virtual processa-se um referente mais descolado. Esse pode parecer mais ou menos descolado da imagem do "real" em função das estratégias utilizadas. Mesmo com o conhecimento disseminado no mundo atual sobre a falácia do valor documental dos veículos de informação, estabelece-se uma espécie de contrato de cumplicidade entre estes e os seus leitores com base no qual a relação de leitura se orienta em função dos dispositivos discursivos colocados em operação.

Essa característica do fotojornalismo, que não é exclusiva da contemporaneidade, mas se reatualiza no mundo atual sobretudo a partir da década de 80 , instaura o leitor na posição de um contemplador de imagens, alguém que se detém diante de uma foto para refletir sobre sua própria funcionalidade no contexto do jornal. Não se quer apenas ver o fato descrito; quer-se sobretudo compreendê-lo contextualmente numa forma de economia da informação. Podemos dizer que hoje, pela noção cada vez mais freqüente de que a imagem é imagem, mesmo a fotográfica; pela concorrência cada vez maior com outras imagens, inclusive de efeitos de presença mais atuantes, não seja o lingüístico que fixa os sentidos da mesma, mas ela que se abre inevitavelmente para uma pluralidade de sentidos, provocando mergulhos nos vários sistemas da cultura, ativando saberes diversos, que alteram completamente sua funcionalidade no sistema das trocas simbólicas.

A convivência com fotografias de imprensa pode constituir um aprendizado semiótico para vê-las como linguagens, ainda quando estamos assujeitados à sua pretensa representação da realidade. Ver na imagem apenas uma ilustração, ou projeção do verbal, por ele 
reduzida a seus sentidos denotados, seria atribuir-lhe um uma feição utópica de imagem inocente, o que nos leva, cada vez mais, a aprender a retirá-la do estado adâmico de que falava Barthes. (1990, p. 35).

\section{Bibliografia}

BARTHES, R. 1990. A retórica da imagem. In: O óbvio e o obtuso - ensaios críticos III. Rio de Janeiro: Nova Fronteira, p. 27-44.

CASTRO, F. Crossover dreams: sobre la fotografia latinoamericana contemporânea. In: WATRISS, W.; ZAMORA, L. P. (eds.) 1998. Image and memory: photography from Latin América, $1866-$ 1994. Austin: University of Texas Press (in Association with Fotofest 1992), p. 57-96.

EISENSTEIN, S. 1969. Reflexões de um cineasta. Rio de Janeiro: Zahar Editores.

JAKOBSON, R. 1970. Lingüística e comunicação. São Paulo: Cultrix.

LANDOWSKI, E. 1992. A sociedade refletida: ensaios de sociossemiótica. São Paulo: EDUC/Pontes.

FONTANILLE, J. 2005. Significação e visualidade: exercicios práticos. Porto Alegre: Sulina.

FONTCUBERTA, J. 1996. Vidência e evidência. In: Revista IMAGENS. Campinas,SP: Ed. da UNICAMP, $\mathrm{n}^{\circ} 7$, maio/agosto, p. 8-15.

FLOCH, J. M. 1986. Les formes de l'empreinte. Périgueux: Pierre Fanlac.

OLIVEIRA, E. 2005. O instante do fotojornalismo. In: Photógrafos - Revista brasileira de fotografia. São Paulo: Art\&Cia Propaganda, n 05, Ano I, 2005, p. 14-27.

Revista Cuartoscuro, abr-may

Disponível em: http://www.cuartoscuro.com.mx/71/artículos.html. Acesso em: 19 dez. 2005. 